\title{
Influences Of Heider Balance On Knowledge, Attitude, Practice And Life Quality In Permanent Urostomy Patients
}

\author{
Hao-yu Zou ( $\square$ meihaoshano@yeah.net) \\ Hunan Provincial People's Hospital \\ Liu-yi Zhang \\ Medical College of Hunan Mormal University \\ Yue-lan Qin \\ Hunan Provincial People's Hospital \\ Ping Li \\ Hunan Provincial People's Hospital \\ Li Zhang \\ Hunan Provincial People's Hospital \\ Ke Yang \\ Hunan Provincial People's Hospital
}

\section{Research Article}

Keywords: Bladder cancer, Urostomy, Heider balance, Knowledge, attitude and practice, Out-hospital intervention, Life quality

Posted Date: June 18th, 2021

DOI: https://doi.org/10.21203/rs.3.rs-536394/v1

License: @ (1) This work is licensed under a Creative Commons Attribution 4.0 International License. Read Full License 


\section{Abstract}

Objective: To explore the influences of out-hospital intervention based on Heider balance on knowledge, attitude, practice (KAP) and life quality in permanent urostomy patients.

Methods: Totally 124 patients underwent permanent urostomy in our hospital from January 2016 to December 2019 were included into this study. These patients were divided into the observation group (62 cases) and the control group (62 cases) according to the method of out-hospital intervention. The control group received routine out-hospital intervention, meanwhile the observation group received out-hospital intervention based on Heider balance. The standard-reaching rate of KAP, the score of WHO quality of life-100 (WHOQOL-100) and the complications of urostomy before discharge and at 6 months after discharge were compared in the two groups.

Results: Before discharge, there were no significant differences of standard-reaching rate of KAP and WHOQOL-100 score between the two groups ( $P>0.05)$. At 6 months after discharge, the standard-reaching rates of the 16 items of KAP (including procedure of pouch replacement, methods of connecting and shutting of pouch, dealing with pouch leakage, skin care of stoma, purchase and storage of pouch, etc.) in the observation group were significantly higher than those in the control group; The scores of more than 10 items of WHOQOL-100 (including energy and fatigue, sleep and rest, positive feelings, thinking, learning, memory and concentration, self-esteem, etc.) in the observation group were significantly higher than those in the control group. The rate of complications in the observation group was significantly lower than that in the control group, all these above differences were statistically significant $(P<0.05)$.

Conclusion: The out-hospital intervention based on Heider balance can reduce the rate of ostomy complications, improve KAP of urostomy and life quality. These merits make the Heider balance to be an attractive approach in guidance of out-hospital intervention for urostomy patients.

\section{Introduction}

Bladder cancer is one of the most common types of urinary cancer, the urinary diversion is routinely performed after radical cystectomy for the muscle-invasive or high risk metastatic bladder cancer ${ }^{[1]}$. After urinary diversion, a urostomy is a stoma created to divert urine in the abdominal wall after the bladder has been resected. Thus, functional and physical changes from cancer patients will result in psychological anxiety and sense of inferiority, which may threaten their mental and physical health ${ }^{[2,3]}$. There is a agreement that the knowledge, attitude and practice (KAP) of patients play a vital role in the management of chronic diseases after discharge, some studies concluded that the self-care ability and life quality will be improved by means of the strengthening of patients' KAP [4-6]. However, the age of bladder cancer patients was relatively older, with problems such as poor acceptance, rigid thinking and inflexible behavior styles ${ }^{[7]}$, which makes it was difficulty for them to achieve satisfying adaptation in psychology and behavior.

The Heider balance was also well known as " P-O-X" model, which was originally proposed by F. Heider in $1946^{[8]}$. The concept of Heider balance mainly involved an equilibrium analysis in terms of positive (friendly or agreement) and negative (hostile or disagreement) relations in triads, and is correlated each other by the connection of the three-body of " P-O-X " [9]. The Heider balance constructed a new perspective on the epistemological relation among subject, object, and media, and created a new conceptual foundation for psychological and behavioral intervention ${ }^{[10]}$. Because conventional out-hospital intervention usually focused on the patients, less attention on the caregiver's influences, it may lead to some negative impacts on out-hospital intervention. In this study, the patients, caregivers, urostomy care were regarded as subject $(P)$, object (O), media (X), respectively. Then, a case-control study was performed to preliminarily investigate the influences of the Heider balance on KAP and life quality in permanent urostomy patients.

\section{Participants And Methods}

\subsection{Participants}


A total of 124 patients who received urostomy in Hunan Provincial People's Hospital from January 2016 to December 2019 were included into this study. According to the method of out-hospital intervention, these patients were divided into the control group and the observation group, and each patient was matched by the observation group by age ( \pm 5 years), gender, education level, the ratio of cases to control of 1:1. Inclusion criteria were set as below: (1) Patients with bladder cancer undergoing radical resection and urinary diversion; (2) Patients without communication disorders and cognitive impairments; (3) Patients who volunteered to participate in this study. Exclusion criteria listed below: (1) Patients with psychiatric disorders or cognitive impairments; (2) Patients with other severe comorbidities; (3) Patients with a life expectancy more than 12 months.

\subsection{Intervention procedure}

Patients in both groups received radical cystectomy and urinary diversion. After admission, all patients were given with routine treatment and nursing, and health education was carried out to introduce the basic knowledge of disease, perioperative preparation, stoma complications and postoperative rehabilitation methods. Before discharge, all patients were asked to learn the pouch replacement, stoma nursing, precautions in dietaries and bathing, daily activities and other related knowledge and skills through demonstration explanation or session. After discharge, a chat tools named WeChat was set up to reply patients' consultations, the telephone follow-up or return visit was carried out once a week in the first month, and once a month in subsequent months. All patients were followed-up for six months at least. Within six months, the control group received routine out-hospital intervention, while the observation group received out-hospital intervention under the guidance of Heider balance.

\subsubsection{Application of Heider balance}

According to framework of Heider balance (P-O-X model) [11], " the patients, caregivers, urostomy care " was set as " $P, O, X$ ", then a triangular unit of Heider balance with " patient $(P)$, caregiver $(0)$ and urostomy care $(X)$ " was established. There was a correlation among " $P, O, X$ " like as : a friend of my friend is my friend, an enemy of my friend is my enemy. Thus, mutual influences were produced in " $\mathrm{P}-\mathrm{O}, \mathrm{O}-\mathrm{X}, \mathrm{P}-\mathrm{X}$ ". The cognition and behavior of patients $(\mathrm{P})$ can be adapted by regulating the relationship between caregivers $(\mathrm{O})$ and urostomy care $(\mathrm{X})$. Assigning a positive (friendly or like) or negative (hostile or dislike) sign to a reciprocated relation between each two sides of the triad unit, positive signed with " + ", negative signed with " - ". If the product of the three edges is " +1 ", triad unit is balanced. Otherwise, the product is " -1 ", the triad unit is unbalanced. The ",,+++ " of the three edges denoted everybody has a positive affect with each other, which was considered as the best status of P-O-X ${ }^{[12]}$. As showed in Fig. 1.

After the establishment of P-O-X triad unit, the status of P-O-X was assessed by means of the relationships among patients, caregivers, urostomy care. If the relationships is not in a balanced status of P-O-X, the reasons of unbalanced status should be detected, further improving measures should be adopted subsequently. For example, a caregiver lacks of nutrition knowledge and cooking skills, he/she is tired of preparing proper dietaries for his/her patient, the relationship of P-O was assigned as " - ". Then, a healthy education program focused on the nutrition knowledge and cooking skills should be performed. During the out-hospital intervention, the status of patients, caregivers, urostomy care were evaluated per month at least, the unbalanced status is adapted under the supervision of responsible staff. The caregiver was allowed to replace in case of someone who is failed to coordinate.

\subsection{Study parameters}

Baseline data (age, gender, education status, family income, stage of tumor and urostomy type) were collected at the time of entry into the study. A 30-item questionnaire was used to evaluate the standard-reaching rate of KAP for urostomy patients. This questionnaire includes 12 items of stoma knowledge, 9 items of healthy belief, 9 items of healthy behavioral ${ }^{[13]}$. The life quality of the patients was evaluated by WHO Quality of Life-100 (WHOQOL-100) ${ }^{[14]}$. The WHOQOL-100 includes six domains of quality of life: physical, psychological, level of independence, social relation, environment and spirituality. These six domains contain 24 facets, each facet includes 4 items. The each item scored on a Likert scale ranging from 1 to 5 , a higher scores indicating better quality of life.

\subsection{Statistical analysis}

The data were processed by SPSS 25.0 software. The measurement data were presented as mean \pm standard deviation ( $\overline{\mathrm{x}} \pm \mathrm{s})$, using by the $t$ test. The counting data were expressed as frequency and percentages (\%), using by $x^{2}$ test. The ranked data were tested using by the rank sum test. $P<0.05$ indicated the difference was significant. 


\section{Results}

\subsection{Baseline data of patients}

There were no significant differences in gender, age, education status, Marital status and urostomy type between the two groups $(P>$ 0.05). As shown in Table 1.

Table 1 Comparisons of baseline data of patients between two groups $[n(\%)]$ 


\begin{tabular}{|c|c|c|c|c|}
\hline Items & Observation group $(n=62)$ & Control group $(n=62)$ & $\chi^{2} / Z$ & $P$ \\
\hline \multicolumn{5}{|l|}{ Gender } \\
\hline Male & $45(72.58)$ & $45(72.58)$ & \multirow[t]{2}{*}{0.000} & \multirow[t]{2}{*}{1.000} \\
\hline Female & $17(27.42)$ & $17((27.42)$ & & \\
\hline \multicolumn{5}{|l|}{ Age (years) } \\
\hline$<44$ & 10(16.13) & $9(14.52)$ & \multirow[t]{3}{*}{0.154} & \multirow[t]{3}{*}{0.926} \\
\hline $44-59$ & $23(37.10)$ & $25(40.32)$ & & \\
\hline$\geq 60$ & $29(46.77)$ & $28(45.16)$ & & \\
\hline \multicolumn{5}{|l|}{ Education level } \\
\hline Elementary & 12(19.35) & 12(19.35) & \multirow[t]{3}{*}{0.000} & \multirow[t]{3}{*}{1.000} \\
\hline Junior/Senior high & $32(51.62)$ & $32(51.62)$ & & \\
\hline College/University & 18(29.03) & 18(29.03) & & \\
\hline \multicolumn{5}{|l|}{ Marital status } \\
\hline Married & $40(64.52)$ & $34(54.84)$ & \multirow[t]{3}{*}{1.211} & \multirow[t]{3}{*}{0.546} \\
\hline Divorced & $12(19.35)$ & $15(24.19)$ & & \\
\hline Widowed & 10(16.13) & $13(20.97)$ & & \\
\hline \multicolumn{5}{|c|}{ Family income (CNY/month) } \\
\hline$<10000$ & 12(19.35) & 10(16.13) & \multirow[t]{4}{*}{0.609} & \multirow[t]{4}{*}{0.894} \\
\hline $10000-20000$ & $33(53.23)$ & $36(58.06)$ & & \\
\hline$>20000$ & $14(22.58)$ & $12(19.35)$ & & \\
\hline Not informed & $3(4.84)$ & $4(6.45)$ & & \\
\hline \multicolumn{5}{|l|}{ Caregivers } \\
\hline Family members & $45(72.58)$ & $39(62.90)$ & \multirow[t]{2}{*}{1.329} & \multirow[t]{2}{*}{0.249} \\
\hline Employed caregivers & $17(25.81)$ & $23(37.10)$ & & \\
\hline \multicolumn{5}{|l|}{ Comorbidities } \\
\hline Hypertension & $22(35.48)$ & 19(30.65) & 0.328 & 0.567 \\
\hline Diabetes & $14(22.58)$ & $16(25.81)$ & 0.176 & 0.675 \\
\hline Others ${ }^{*}$ & $11(17.74)$ & $15(24.19)$ & 0.779 & 0.378 \\
\hline \multicolumn{5}{|l|}{ Urostomy type } \\
\hline Ileal conduit & $55(88.71)$ & $54(87.10)$ & \multirow[t]{3}{*}{0.652} & \multirow[t]{3}{*}{0.722} \\
\hline Bilateral ureterostomy & $3(4.84)$ & $5(8.06)$ & & \\
\hline Unilateral ureterostomy & $4(6.45)$ & $3(4.84)$ & & \\
\hline
\end{tabular}

Note: *Including common gout, gastrointestinal diseases and pulmonary diseases, etc.

\subsection{The standard-reaching rate of KAP}


Before discharge, there were no statistically significant differences between the two groups in standard-reaching rate of each item of KAP $(P>0.05)$. At 6 months after discharge, the standard-reaching rate of the 6 items (basic knowledge of disease, procedure of pouch replacement, dealing with pouch leakage, skin care of stoma, purchase and storage of pouch, dealing with stoma complications) in knowledge, 5 items (optimistic mentality for disease, optimistic mentality for stoma, high trust in medical staff, willingness to correct bad habits, confidence in maintaining healthy behavior) in attitude, and 5 items (maintaining in healthy dietary habit, maintaining in healthy behavior, regular learning from relevant books, experienced in pouch replacement, experienced in care of stoma) in behavior of the observation group were significantly higher than those of the control group, the difference was statistically significant $(P<0.05)$. As shown in Table 2.

Table 2 Comparisons of standard-reaching rate of KAP between two groups [n(\%)]

\subsection{Comparisons of life quality}

Before discharge, no significant differences were observed in WHOQOL-100 score between the two groups $(P>0.05)$. At 6 months after discharge, there were significant differences in the scores of 14 items of WHOQOL-100 between the two groups, including energy and fatigue, sleep and rest, positive feelings, thinking, learning, memory and concentration, self-esteem, body image and appearance, negative feelings, mobility, activities of daily living, dependence on medical support, personal relationships, social support, health and social care: availability and quality, quality of life from the view point, and the scores of most items mentioned above in the observation group were higher than those of the control group, the differences were statistically significant $(P<0.05)$. As shown in Table 3.

Table 3 Comparisons of quality of life between two groups ( $x \pm s)$

\subsection{Comparisons of complications}

During the out-hospital intervention, 11 cases of stoma complications occurred in the observation group, including 4 cases of dermatitis, 2 cases of stoma infection, 2 cases of skin stripping, 2 cases of stoma retraction and 1 case of fistula. Among them, 2 complications existed in 4 patients, involving 7 patients, accounting for $11.29 \%$ (7/62). In the control group, a total of 22 cases of stoma complications occurred, including 7 cases of dermatitis, 4 cases of stoma infection, 3 cases of skin stripping, 3 cases of stoma stenosis, 2 cases of stoma retraction, 2 cases of granulomatosis and 1 cases of fistula. Among them, 5 complications existed in 1 patients, involving 17 patients, accounting for $27.42 \%$ (17/62). The complication rate in the observation group was lower than that in the control group, and the difference was statistically significant $\left(x^{2}=5.167, P=0.023\right)$.

\section{Discussion}

Radical cystectomy and urinary diversion remain the main treatment procedures for muscle-invasive or high-risk non-muscle invasive bladder cancer ${ }^{[15]}$. Postoperative urostomy education program is common and necessary, but most of patients were in a struggle to maintain well self-management in practice. The application of KAP is a way to inspect the changes in people's thinking and behavior. Evidence showed that knowledge is the foundation of attitude and behavior changes, while positive attitude may further encourage positive changes in behavior ${ }^{[16,17]}$. So, patients' knowledge of disease may influence their attitudes and practices towards the disease. Because urostomy care has a long-lasting burden for patients and their caregivers, patients always lack of professional care support from medical institutions after discharge. Therefore, a urostomy education program for patients and their caregivers should be developed to meet this demand.

Relationships among a focal person (patients, $\mathrm{P}$ ), another person (caregivers, 0 ), and a media (urostomy care, $\mathrm{X}$ ) were the main focus of the Heider balance (P-O-X model). There were eight possible component status, including four balanced and four unbalanced ${ }^{[18]}$ : If all three reciprocated relations were positive or two of them were negative, the triad unit were balanced, including " $P+O, P+X, O+X$ ”, “ $P+O, P-X, O-X$ ”, " $P-O, P+X, O-X$ ”, " $P-O, P-X, O+X$ ”; If two of the three reciprocated relations were positive or all of them were negative, the triad unit were unbalanced, including " $P+O, P+X, O-X$ ", " $P+O, P-X, O+X$ ", " $P-O, P+X$, 


\begin{tabular}{|c|c|c|c|c|c|c|c|c|}
\hline \multirow[t]{2}{*}{ Items } & \multicolumn{4}{|c|}{ Before discharge } & \multicolumn{4}{|c|}{ At 6 months after discharge } \\
\hline & $\begin{array}{l}\text { Observation } \\
\text { group }(n=62)\end{array}$ & $\begin{array}{l}\text { Control } \\
\text { group }(n=62)\end{array}$ & $\chi^{2}$ & $P$ & $\begin{array}{l}\text { Observation } \\
\text { group }(n=62)\end{array}$ & $\begin{array}{l}\text { Control } \\
\text { group }(n=62)\end{array}$ & $\chi^{2}$ & $P$ \\
\hline \multicolumn{9}{|l|}{ Knowledge } \\
\hline $\begin{array}{l}\text { Basic knowledge of } \\
\text { disease }\end{array}$ & $27(43.55)$ & $30(48.39)$ & 0.292 & 0.589 & $55(88.71)$ & $42(67.74)$ & 8.002 & 0.005 \\
\hline $\begin{array}{l}\text { Importance of stoma } \\
\text { operation }\end{array}$ & $48(77.42)$ & $53(85.48)$ & 1.334 & 0.248 & $54(87.10)$ & $57(91.94)$ & 0.773 & 0.379 \\
\hline Observation of stoma & $37(59.68)$ & $35(56.45)$ & 0.132 & 0.716 & 49(79.03) & $47(75.81)$ & 0.185 & 0.668 \\
\hline $\begin{array}{l}\text { Procedure of } \\
\text { pouch replacement }\end{array}$ & $41(66.13)$ & $44(70.97)$ & 0.337 & 0.562 & $56(90.32)$ & $45(72.583)$ & 6.459 & 0.011 \\
\hline $\begin{array}{l}\text { Emptying of pouch } \\
\text { drainage }\end{array}$ & $38(61.29)$ & $32(51.61)$ & 1.181 & 0.277 & $59(95.16)$ & $54(87.10)$ & 2.494 & 0.114 \\
\hline $\begin{array}{l}\text { Measuring of stoma } \\
\text { size }\end{array}$ & $40(64.52)$ & $40(64.52)$ & 0.000 & 1.000 & $54(87.10)$ & $49(79.03)$ & 1.433 & 0.231 \\
\hline $\begin{array}{l}\text { Connecting and } \\
\text { shutting of pouch }\end{array}$ & $33(53.23)$ & $31(50.00)$ & 0.129 & 0.719 & $52(83.87)$ & $45(72.58)$ & 2.320 & 0.128 \\
\hline $\begin{array}{l}\text { Application of ancillary } \\
\text { devices }\end{array}$ & $25(41.67)$ & $26(41.94)$ & 0.033 & 0.855 & $50(80.65)$ & $46(74.19)$ & 0.738 & 0.390 \\
\hline $\begin{array}{l}\text { Dealing with pouch } \\
\text { leakage }\end{array}$ & $21(33.87)$ & $22(35.48)$ & 0.036 & 0.850 & 49(79.03) & $36(58.06)$ & 6.322 & 0.012 \\
\hline Skin care of stoma & $31(50.00)$ & $29(46.77)$ & 0.129 & 0.719 & $56(90.32)$ & $44(70.97)$ & 7.440 & 0.006 \\
\hline $\begin{array}{l}\text { Purchase and storage } \\
\text { of pouch }\end{array}$ & $32(51.61)$ & $36(58.06)$ & 0.521 & 0.470 & $51(82.26)$ & $39(62.90)$ & 5.835 & 0.016 \\
\hline $\begin{array}{l}\text { Dealing with stoma } \\
\text { complications }\end{array}$ & $23(37.10)$ & $22(35.48)$ & 0.035 & 0.852 & $50(80.65)$ & $38(61.29)$ & 5.636 & 0.018 \\
\hline \multicolumn{9}{|l|}{ Attitude } \\
\hline $\begin{array}{l}\text { Optimistic mentality for } \\
\text { disease }\end{array}$ & $34(54.84)$ & $31(50.00)$ & 0.291 & 0.590 & $52(83.87)$ & $37(59.68)$ & 8.957 & 0.003 \\
\hline $\begin{array}{l}\text { Optimistic mentality for } \\
\text { stoma }\end{array}$ & $32(51.61)$ & $27(43.55)$ & 0.808 & 0.369 & 49(79.03) & $36(58.06)$ & 6.322 & 0.012 \\
\hline $\begin{array}{l}\text { Enthusiasm for } \\
\text { rehabilitation plan }\end{array}$ & $39(62.90)$ & $37(59.68)$ & 0.136 & 0.712 & $45(72.58)$ & $39(62.90)$ & 1.329 & 0.249 \\
\hline $\begin{array}{l}\text { High trust in medical } \\
\text { staff }\end{array}$ & $44(70.97)$ & $47(75.81)$ & 0.372 & 0.542 & $57(91.94)$ & $48(77.42)$ & 5.035 & 0.025 \\
\hline $\begin{array}{l}\text { High trust in their } \\
\text { caregivers }\end{array}$ & $40(64.52)$ & $41(66.13)$ & 0.036 & 0.850 & $53(85.48)$ & $51(82.26)$ & 0.238 & 0.625 \\
\hline $\begin{array}{l}\text { Willingness to correct } \\
\text { bad habits }\end{array}$ & $38(61.29)$ & $35(56.45)$ & 0.300 & 0.584 & $55(88.71)$ & $40(64.52)$ & 10.127 & 0.001 \\
\hline $\begin{array}{l}\text { Willingness to help } \\
\text { others }\end{array}$ & $33(53.23)$ & $34(54.84)$ & 0.032 & 0.857 & $47(75.81)$ & $43(69.35)$ & 0.648 & 0.421 \\
\hline $\begin{array}{l}\text { Willingness to correct } \\
\text { negative emotion }\end{array}$ & $25(40.32)$ & $29(46.77)$ & 0.525 & 0.469 & $50(80.65)$ & $47(75.81)$ & 0.426 & 0.514 \\
\hline $\begin{array}{l}\text { Confidence in } \\
\text { maintaining healthy } \\
\text { behavior }\end{array}$ & $36(58.06)$ & $34(54.84)$ & 0.131 & 0.717 & $56(90.32)$ & $43(69.35)$ & 8.467 & 0.004 \\
\hline Behavior & & & & & & & & \\
\hline
\end{tabular}




\begin{tabular}{|lcccccccc|}
$\begin{array}{l}\text { Maintaining in healthy } \\
\text { dietary habit }\end{array}$ & $32(46.77)$ & $33(53.23)$ & 0.516 & 0.472 & $58(93.55)$ & $49(79.03)$ & 5.522 & 0.019 \\
\hline $\begin{array}{l}\text { Maintaining in healthy } \\
\text { behavior }\end{array}$ & $31(50.00)$ & $38(61.29)$ & 1.601 & 0.206 & $55(88.71)$ & $42(67.74)$ & 8.002 & 0.005 \\
\hline $\begin{array}{l}\text { Regular learning from } \\
\text { relevant books }\end{array}$ & $13(20.97)$ & $14(22.58)$ & 0.047 & 0.828 & $42(67.74)$ & $30(48.39)$ & 4.769 & 0.029 \\
$\begin{array}{l}\text { Regular learning from } \\
\text { relevant videos }\end{array}$ & $20(32.26)$ & $25(40.32)$ & 0.872 & 0.350 & $43(69.35)$ & $41(66.13)$ & 0.148 & 0.701 \\
\hline $\begin{array}{l}\text { Experienced in } \\
\text { pouch replacement }\end{array}$ & $29(46.77)$ & $27(43.55)$ & 0.130 & 0.718 & $58(93.55)$ & $48(77.42)$ & 6.499 & 0.011 \\
\hline $\begin{array}{l}\text { Experienced in care of } \\
\text { stoma }\end{array}$ & $28(45.16)$ & $29(46.77)$ & 0.032 & 0.857 & $56(90.32)$ & $44(70.97)$ & 7.440 & 0.006 \\
\hline $\begin{array}{l}\text { Regular communicated } \\
\text { with other patients }\end{array}$ & $17(27.42)$ & $18(29.03)$ & 0.040 & 0.842 & $39(62.90)$ & $38(61.29)$ & 0.034 & 0.853 \\
\hline $\begin{array}{l}\text { Highly complying with } \\
\text { doctor's advice }\end{array}$ & $45(72.58)$ & $41(66.13)$ & 0.607 & 0.436 & $57(91.94)$ & $50(80.65)$ & 3.340 & 0.068 \\
\hline \begin{tabular}{l} 
Regular return visit \\
\hline
\end{tabular} & - & - & - & - & $59(95.16)$ & $55(88.71)$ & 1.740 & 0.187 \\
\hline
\end{tabular}

$O+X$ ", "P $-O, P-X, O-X$ ". In this model, relationships were either positive or negative according to the cognitive perceptions of others. Among these status, the " $P+O, P+X, O+X$ " was considered as the best status of $P-O-X$ model with a positive mutual influence. Any other balance or unbalance status can be turned by reversing anyone's attitude, that can explain the feasibility of outhospital intervention based on this model ${ }^{[19]}$. For example, the triad unit were unbalanced with " $P-O, P+X, O+X$ " status, supposing that the caregiver $(0)$ was disgusted of uncomfortable features of pouch drainage from patients $(X)$. Particularly, more attentions should be paid for " $\mathrm{P}-\mathrm{O}$ ", a healthy education program or kind conversation would be carried out for caregivers and patients, so as to rectified the negative attitude.

After six months out-hospital intervention, the standard-reaching rate of the 6 items in knowledge, 5 items in attitude and 5 items in behavior of the observation group were significantly higher than those of the control group, those differences suggested that the outhospital intervention based on Heider balance can obviously rectified the knowledge, attitude and practice comparing with the routine out-hospital intervention. A qualitative systematic review considered that ${ }^{[20]}$ good family support had a positive impact on patients, which can promote positive health outcomes in many chronic diseases. Essentially, this viewpoint was in accordance with the principle of Heider balance, but the application of Heider balance were clearly presented with framework of three-body interactions consisted of patients, disease and caregivers, with the assumption thinking that any edge of triads was equivalent important in the dynamics of network [21]. In a study on Heider balance and KAP model performed by Lou FL, et al [22], they also hold the view that the caregivers should be brought into the intervention, which can improve the level of knowledge and attitude towards pain management in cancer patients, and increase the intervention efficacy for them.

In this study, the findings demonstrated that most of items of WHOQOL-100 in the observation group were significant higher than those of the control group, especially in physical health, psychological, independence level, social relations domain. These results indicated that the out-hospital intervention based on Heider balance can obviously improve life quality of patients. No significant differences were observed in environment domain except for "health and social care: availability and quality", the possible explanation may be that environment factors can not be changed within a short time. The WHOQOL-100 were commonly used in chronic diseases of its efficiency in measuring health-related quality of life, a increase or decrease of life quality after urinary diversion plays a important role in an individual's adaption to life with a stoma ${ }^{[23,24]}$. A study reported that ${ }^{[25]}$ a formal preoperative ostomy education program involved an interactive educational approach can make a promotion in patients' ostomy selfmanagement and post-ostomy life quality. Another study considered that ${ }^{[26]}$ hospital-based home care teams should be created at least 6 months after discharge, so as to improve the patient's life quality in discharged follow-up care. These findings from above studies were basically consistent with the results in our study. A previous study found that ${ }^{[27]}$ a ostomy education program can decrease the rate of complication, this result in support of our findings that well out-hospital intervention can reduce the risk of 


\begin{tabular}{|c|c|c|c|c|c|c|c|c|}
\hline \multirow[t]{2}{*}{ Domain } & \multicolumn{4}{|c|}{ Before discharge } & \multicolumn{4}{|c|}{ At 6 months after discharge } \\
\hline & $\begin{array}{l}\text { Observation } \\
\text { group }(n=62)\end{array}$ & $\begin{array}{l}\text { Control } \\
\text { group }(n=62)\end{array}$ & $t$ & $P$ & $\begin{array}{l}\text { Observation } \\
\text { group }(n=62)\end{array}$ & $\begin{array}{l}\text { Control } \\
\text { group }(n=62)\end{array}$ & $t$ & $P$ \\
\hline \multicolumn{9}{|l|}{ Physical health } \\
\hline Pain and discomfort & $14.01 \pm 3.05$ & $13.70 \pm 4.23$ & 0.468 & 0.641 & $11.32 \pm 4.10$ & $12.38 \pm 3.76$ & 1.500 & 0.136 \\
\hline Energy and fatigue & $14.62 \pm 4.94$ & $14.58 \pm 4.16$ & 0.049 & 0.961 & $16.67 \pm 3.13$ & $14.83 \pm 4.06$ & 2.826 & 0.006 \\
\hline Sleep and rest & $12.88 \pm 3.10$ & $12.13 \pm 3.23$ & 1.319 & 0.190 & $15.95 \pm 2.02$ & $14.12 \pm 3.06$ & 3.930 & 0.000 \\
\hline \multicolumn{9}{|l|}{ Psychological } \\
\hline Positive feelings & $10.16 \pm 3.86$ & $9.43 \pm 3.41$ & 1.116 & 0.267 & $14.76 \pm 3.83$ & $13.04 \pm 3.74$ & 2.530 & 0.013 \\
\hline $\begin{array}{l}\text { Thinking, learning, memory } \\
\text { and concentration }\end{array}$ & $13.57 \pm 5.15$ & $13.26 \pm 4.37$ & 0.361 & 0.718 & $15.60 \pm 4.43$ & $13.32 \pm 4.21$ & 2.938 & 0.004 \\
\hline Self-esteem & $12.33 \pm 4.28$ & $12.56 \pm 5.04$ & 0.274 & 0.785 & $14.55 \pm 5.02$ & $12.73 \pm 4.38$ & 2.151 & 0.033 \\
\hline Body image and appearance & $9.07 \pm 3.54$ & $8.39 \pm 3.24$ & 1.193 & 0.235 & $13.86 \pm 3.31$ & $12.33 \pm 3.75$ & 2.409 & 0.018 \\
\hline Negative feelings & $14.51 \pm 4.35$ & $15.26 \pm 3.97$ & 1.003 & 0.318 & $11.82 \pm 3.45$ & $13.34 \pm 2.80$ & 2.694 & 0.008 \\
\hline \multicolumn{9}{|l|}{ Independence level } \\
\hline Mobility & $10.83 \pm 3.79$ & $10.76 \pm 4.11$ & 0.099 & 0.922 & $13.86 \pm 3.84$ & $12.03 \pm 4.23$ & 2.522 & 0.013 \\
\hline Activities of daily living & $11.86 \pm 3.56$ & $12.38 \pm 3.78$ & 0.789 & 0.432 & $14.97 \pm 4.26$ & $12.41 \pm 3.64$ & 3.597 & 0.000 \\
\hline $\begin{array}{l}\text { Dependence on medical } \\
\text { support }\end{array}$ & $15.28 \pm 4.03$ & $14.24 \pm 4.35$ & 1.381 & 0.170 & $11.70 \pm 3.79$ & $13.58 \pm 4.22$ & 2.610 & 0.010 \\
\hline Work capacity & $12.09 \pm 3.67$ & $12.41 \pm 3.80$ & 0.477 & 0.634 & $11.73 \pm 4.02$ & $12.38 \pm 4.39$ & 0.860 & 0.392 \\
\hline \multicolumn{9}{|l|}{ Social relations } \\
\hline Personal relationships & $14.13 \pm 3.82$ & $13.76 \pm 3.14$ & 0.589 & 0.557 & $16.74 \pm 2.14$ & $15.53 \pm 2.93$ & 2.626 & 0.010 \\
\hline Social support & $14.56 \pm 3.13$ & $15.09 \pm 4.38$ & 0.775 & 0.440 & $17.13 \pm 3.50$ & $15.14 \pm 3.19$ & 3.309 & 0.001 \\
\hline Sexual activity & $12.53 \pm 2.98$ & $13.40 \pm 3.70$ & 1.445 & 0.151 & $8.98 \pm 2.38$ & $9.71 \pm 2.74$ & 1.584 & 0.116 \\
\hline \multicolumn{9}{|l|}{ Environment } \\
\hline Physical safety and security & $12.83 \pm 3.65$ & $13.00 \pm 3.45$ & 0.267 & 0.790 & $12.04 \pm 3.35$ & $11.73 \pm 3.88$ & 0.476 & 0.635 \\
\hline Home environment & $12.34 \pm 3.80$ & $12.26 \pm 3.79$ & 0.117 & 0.907 & $12.27 \pm 3.77$ & $12.83 \pm 3.98$ & 0.804 & 0.423 \\
\hline Financial resources & $13.74 \pm 4.11$ & $13.04 \pm 3.88$ & 0.975 & 0.331 & $13.98 \pm 4.03$ & $12.96 \pm 4.24$ & 1.373 & 0.172 \\
\hline $\begin{array}{l}\text { Health and social care: } \\
\text { availability and quality }\end{array}$ & $11.98 \pm 3.53$ & $12.13 \pm 4.22$ & 0.215 & 0.830 & $14.56 \pm 4.46$ & $11.70 \pm 3.15$ & 4.124 & 0.000 \\
\hline $\begin{array}{l}\text { Opportunities to get new } \\
\text { information /skills }\end{array}$ & $9.65 \pm 2.46$ & $10.22 \pm 2.83$ & 1.197 & 0.234 & $10.85 \pm 2.79$ & $11.14 \pm 3.15$ & 0.543 & 0.588 \\
\hline $\begin{array}{l}\text { Opportunities for } \\
\text { recreation and leisure }\end{array}$ & $11.33 \pm 3.54$ & $12.35 \pm 3.60$ & 1.591 & 0.114 & $12.57 \pm 2.96$ & $13.29 \pm 3.51$ & 1.235 & 0.219 \\
\hline Physical environment & $10.87 \pm 3.17$ & $11.36 \pm 2.97$ & 0.888 & 0.376 & $12.46 \pm 4.38$ & $12.10 \pm 4.06$ & 0.475 & 0.636 \\
\hline Transportation & $10.03 \pm 2.99$ & $9.89 \pm 3.72$ & 0.231 & 0.818 & $10.11 \pm 3.89$ & $10.35 \pm 3.66$ & 0.354 & 0.724 \\
\hline \multicolumn{9}{|l|}{ Appendixes } \\
\hline $\begin{array}{l}\text { Spirituality/religion/personal } \\
\text { beliefs }\end{array}$ & $15.46 \pm 3.74$ & $15.96 \pm 3.36$ & 0.783 & 0.435 & $15.62 \pm 3.87$ & $16.16 \pm 3.68$ & 0.796 & 0.427 \\
\hline $\begin{array}{l}\text { Quality of life from the view } \\
\text { point }\end{array}$ & $11.28 \pm 3.73$ & $10.91 \pm 3.97$ & 0.535 & 0.594 & $14.65 \pm 4.03$ & $12.42 \pm 3.84$ & 3.154 & 0.002 \\
\hline
\end{tabular}


complication after discharge. Indeed, as others reported ${ }^{[28,29]}$, patients may benefit from more education, and almost half of patients sought the help of an professional ostomy care, especially these patients with permanent urostomy.

In summary, the out-hospital intervention based on Heider balance can help to strengthen patients' understanding and mastering on knowledge, improve attitude and practice, reduce the rate of stoma complications, consequently promote the life quality of patients. These merits make the Heider balance to be an attractive approach in guidance of out-hospital intervention in urostomy patients. However, this study was a preliminary exploration of the out-hospital intervention based on the Heider balance, which still has a certain distance for standardized application in clinical pathway. Therefore, the application procedure of Heider balance in outhospital intervention needs to be supplemented in further study.

\section{Declarations}

Funding: No support from any funding in this study.

Conflicts of interest/Competing interests: None of the authors have any conflicts of interest to declare.

Availability of data and material: Data and material are available from the corresponding author on reasonable request.

Code availability: N/A.

Authors' contributions: Hao-yu Zou, Liu-yi Zhang, Yue-lan Qin and Ke Yang contributed to the study conception and design. Material preparation, data collection, and analysis were performed by Hao-yu Zou, Ping Li and Li Zhang, Hao-yu Zou and Ke Yang wrote and revised the paper. Liu-yi Zhang and Yue-lan Qin performed the writing-review and editing. All authors read and approved the final manuscript.

Ethics approval: The study was approved by the ethics committee of Hunan Provincial People's Hospital, and the procedures almost were part of the routine care.

Consent to participate: Informed consent was obtained from participants included in the study.

Consent for publication: N/A.

\section{References}

1. González Del Alba A, De Velasco G, Lainez N et al (2019) SEOM clinical guideline for treatment of muscle-invasive and metastatic urothelial bladder cancer (2018) [J]. Clin TransI Oncol 21(1):64-74

2. Furukawa C, Morioka I. Health-Related Quality of Life and Sleep Disorders in Patients With a Urostomy: Is There a Relationship? [J]. J Wound Ostomy Continence Nurs,2017,44(4):358-362

3. Vartolomei L, Vartolomei MD, Shariat SF (2020) Bladder Cancer: Depression, Anxiety, and Suicidality Among the Highest-risk Oncology Patients[J]. Eur Urol Focus 6(6):1158-1161

4. Liu MH, Wang $\mathrm{CH}$, Huang YY et al (2014) A correlational study of illness knowledge, self-care behaviors, and quality of life in elderly patients with heart failure[J]. J Nurs Res 22(2):136-145

5. Wong FMF. Factors Associated with Knowledge, Attitudes, and Practices Related to Oral Care Among the Elderly in Hong Kong Community[J]. Int J Environ Res Public Health,2020,17(1):1-15

6. Stellefson M, Paige SR, Alber JM et al (2019) Association Between Health Literacy, Electronic Health Literacy, Disease-Specific Knowledge, and Health-Related Quality of Life Among Adults With Chronic Obstructive Pulmonary Disease: Cross-Sectional Study[J]. J Med Internet Res 21(6):e12165

7. Rozas NS, Sadowsky JM, Jeter CB (2017) Strategies to improve dental health in elderly patients with cognitive impairment: A systematic review[J]. J Am Dent Assoc 148(4):236-245

8. Heider F (1946) Attitudes and cognitive organization[J]. J Psychol 21(1):107-112

9. Antal T, Krapivsky PL, Redner S (2005) Dynamics of social balance on networks[J]. Phys Rev E Stat Nonlin Soft Matter Phys 72(3Pt2):036121

Page $10 / 12$ 
10. Wieser M (2014) Remembering the "lens": visual transformations of a concept from Heider to Brunswik[J]. Hist Psychol 17(2):83-104

11. Kulakowski K, Gawronski P, Gronek P (2005) The Heider balance - a continuous approach[J]. Int J Mod Phys C 16(5):707-707

12. Kulakowski K (2007) Some Recent Attempts to Simulate the Heider Balance Problem[J]. Computing in Science Engineering $9(4): 1-14$

13. Qiao GM, Zhang XL, Wang YM et al (2014) Development of the health education standards for patients with cystostomy[J]. Chin J Nurs 49(9):1058-1061

14. Li L, Young D, Xiao S et al (2004) Psychometric properties of the WHO Quality of Life questionnaire (WHOQOL-100) in patients with chronic diseases and their caregivers in China[J]. Bull World Health Organ 82(7):493-502

15. Khan MS, Omar K, Ahmed K et al (2020) Long-term Oncological Outcomes from an Early Phase Randomised Controlled Threearm Trial of Open, Robotic, and Laparoscopic Radical Cystectomy (CORAL)[J]. Eur Urol 77(1):110-118

16. Adebimpe WO (2016) Knowledge, Attitude, and Practice of Use of Safety Precautions Among Health Care Workers in a Nigerian Tertiary Hospital, 1 Year After the Ebola Virus Disease Epidemic[J]. Ann Glob Health 82(5):897-902

17. ALBalawi HB, Alali NM (2020) Evaluation of Knowledge, Attitude, and Practices toward the Outbreak Pandemic (COVID-19) Virus Disease among Ophthalmologists: A Cross-Sectional Study[J]. Middle East Afr J Ophthalmol 27(3):164-171

18. Molet M, Craddock P, Grassart A. An application of Heider's P-O-X balance model to change evaluative conditioning effects[J]. Learning \& Motivation, 2015, 51(1):pp 43-49

19. Chiang YS, Chen YW, Chuang WC et al (2020) Triadic balance in the brain: Seeking brain evidence for Heider's structural balance theory[J]. Social Networks 63(1):80-90

20. Whitehead L, Jacob E, Towell A et al (2018) The role of the family in supporting the self-management of chronic conditions: A qualitative systematic review[J]. J Clin Nurs 27(1-2):22-30

21. Bagherikalhor M, Kargaran A, Shirazi AH et al. Heider balance under disordered triadic interactions[J]. Phys Rev E, 2021,103(3 1):032305

22. Lou FL, Shang SM. Attitudes to pain management towards cancer patients and its influencing factors based on analysis of theoretical perspectives with"S-O-R"model, Heider balance theory and KAP Model[J]. Chin J Prac Nur,2018,34(13):1008-1015

23. Cengiz B, Bahar Z (2017) Perceived Barriers and Home Care Needs When Adapting to a Fecal Ostomy: A Phenomenological Study[J]. J Wound Ostomy Continence Nurs 44(1):63-68

24. Lin CY, Lee TY, Sun ZJ et al (2017) Development of diabetes-specific quality of life module to be in conjunction with the World Health Organization quality of life scale brief version (WHOQOL-BREF) [J]. Health Qual Life Outcomes 15(1):167-187

25. Wulff-Burchfield EM, Potts M, Glavin K, Mirza M. A qualitative evaluation of a nurse-led pre-operative stoma education program for bladder cancer patients[J]. Support Care Cancer, 2021. Epub ahead of print

26. Cengiz B, Bahar Z, Canda AE (2020) The Effects of Patient Care Results of Applied Nursing Intervention to Individuals With Stoma According to the Health Belief Model[J]. Cancer Nurs 43(2):87-96

27. Liao JJ, Meng YX, Li JR et al (2017) Evaluation of effect of health education pathway intervention on quality of life, health belief and health behaviors among urostomy patients[J]. Chin J Heal Educ 33(8):749-755

28. Su X, Qin F, Zhen L et al (2016) Self-efficacy and associated factors in patients with temporary ostomies: a cross-sectional survey[J]. J Wound Ostomy Cont Nurs 43(6):623-629

29. Maydick-Youngberg D (2017) A Descriptive Study to Explore the Effect of Peristomal Skin Complications on Quality of Life of Adults With a Permanent Ostomy[J]. Ostomy Wound Manage 63(5):10-23

\section{Figures}




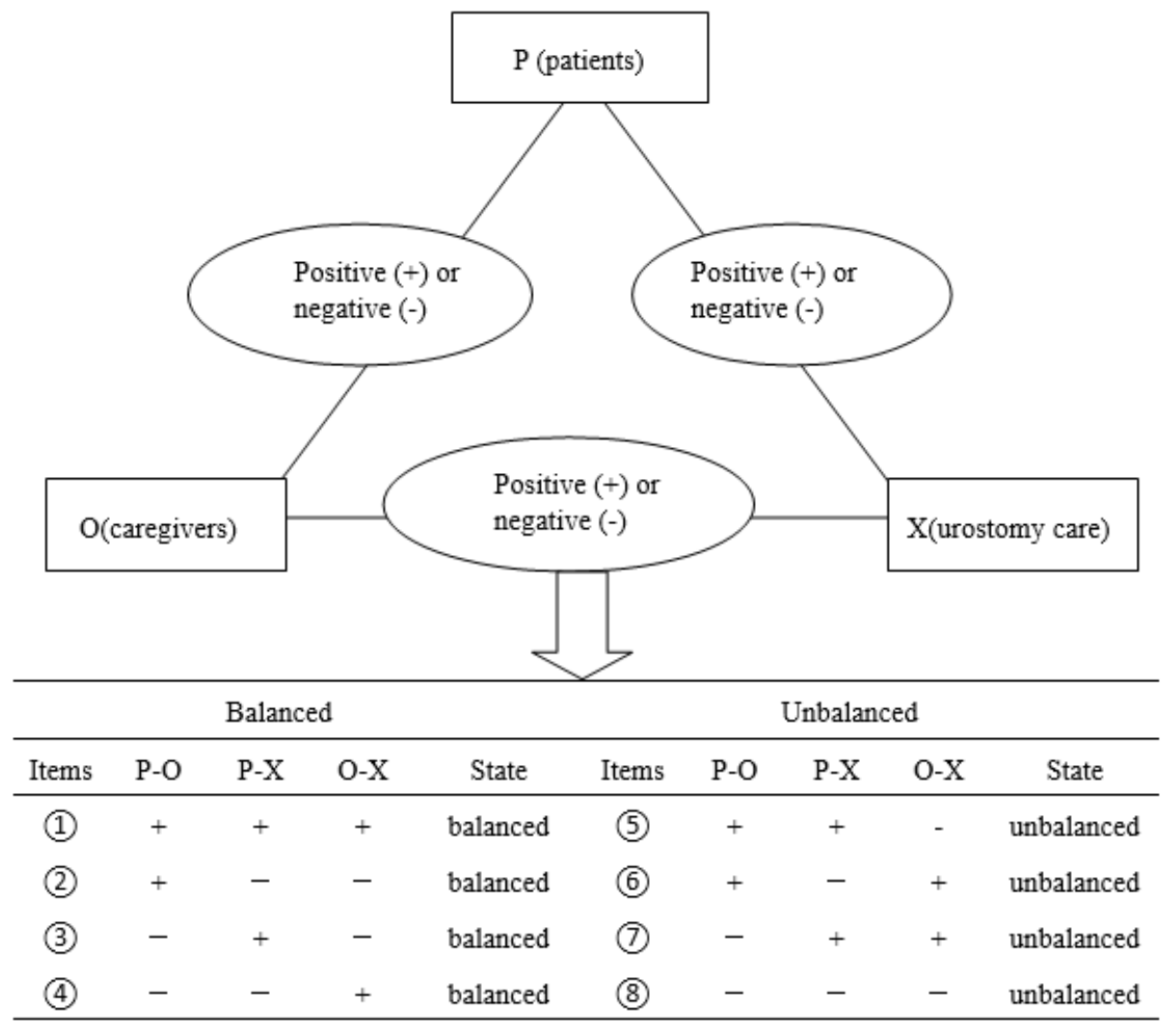

\section{Figure 1}

The structure of Heider balance and assessment of status 